\title{
Short Communication: Antibiotic Residues in Milk Following the Use of Intravaginal Sponges for Estrus Synchronization in Dairy Ewes
}

\author{
M. I. Berruga, ${ }^{* 1}$ A. Rodriguez, $†$ R. Rubio, ${ }^{*}$ R. Gallego, $\dagger$ and A. Molina* \\ *Departamento de Ciencia y Tecnología Agroforestal y Genética, Sección de Calidad Alimentaria, IDR, ETSIA, Universidad de Castilla-La \\ Mancha, 02071 Albacete, Spain \\ †Asociación de Ganaderos de Raza Manchega, AGRAMA, Avenida Gregorio Arcos, s/n 02006 Albacete, Spain
}

\section{ABSTRACT}

The addition of antibiotics to intravaginal sponges used to synchronize ewe estrus is currently a recommended practice for the prevention of posttreatment vaginal infections. Application of this antibiotic treatment is usually done without withdrawal periods for milk, but official pharmaceutical instructions do not consider the extra-label use of antibiotics, which could result in the presence of antibiotic residues in milk. To understand the effects of the use of antibiotics on the performance of these hormonal treatments, milk collected from a group of Manchega ewes estrus synchronized by intravaginally inserted progestagen sponges jointly impregnated with antibiotics (benzyl penicillin procaine: 1,000,000 IU/25 sponges plus DH-streptomycin: $1 \mathrm{~g} / 25$ sponges) was evaluated for antibiotic residue persistence with 5 types of antibiotic screening tests (BRT, Copan CMT, Delvotest MSC, Eclipse 100, and New SNAP Beta-Lactams). Time to antibiotic residue depletion was established by a logistic regression model, and a significant response to milking order was observed in all methods. Positive or doubtful tests were observed after the insertion of intravaginal sponges for all assay screening tests at the time of the first milking and sometimes afterwards.

Key words: antibiotic residue, screening method, dairy ewe, estrus synchronization

In the Mediterranean dairy sheep, breeding usually takes place during lactation. The use of AI for genetic improvement schemes in dairy sheep is based on precise estrus synchronization, which is usually accomplished by use of intravaginally inserted progestagen sponges (Barillet et al., 2001; Ugarte et al., 2002). Afterward, $\mathrm{AI}$ or natural or ram-directed mating can be conducted. Within the boundaries of these reproductive perfor-

Received February 7, 2008

Accepted June 5, 2008.

${ }^{1}$ Corresponding author: mariaisabel.berruga@uclm.es mance protocols there is a potential risk of vaginal infection after intravaginal sponge application, and it is usually recommended to add antibiotics to the bag of sponges, either in powder or spray form, before placement in the vagina to prevent vaginitis in ewes (Kridli et al., 2006; Suárez et al., 2006). The extra application of a low quantity of antibiotic present in these sponges is not considered in the length of the withdrawal period, and its use as a preventive treatment could potentially result in the presence of antibiotic residues in milk.

The use of antimicrobial substances in ewe milk can have serious effects on public health and dairy product quality; antibiotic residues in milk may cause antibiotic resistances, allergies in consumers, or even defects in fermented dairy products (Mourot and Loussouarn, 1981; EMEA, 1999). Residue levels are normally checked by screening methods (Mitchell et al., 1998) that indicate the presence of milk contamination from antibiotic residues that register above the maximum residue limits (MRL) established by European Union Regulation EEC 2377/90. Microbial inhibition tests have been employed to evaluate the antibiotic depletion time in ewe milk (Berruga et al., 2003; Molina et al., 2003a).

Limited information is available on the presence of antibiotic residues in milk following intravaginal administration. Henningson et al. (1963) described the absence of residues in milk from treated cows during the intravaginal deposition of furacin (nitrofurazone) suppositories over a period of $3 \mathrm{wk}$. Other authors have studied the persistence of antibiotics in cow milk when used for reproductive tract infections, mainly in the uterus. Some of them have found evidence of antibiotic residues in milk in the first milkings (24 to $48 \mathrm{~h}$ ) after the intrauterine administration of suppositories, infusions, or tablets of penicillin, streptomycin, or tetracycline (Miller and Bergt, 1974; Black et al., 1979; Bishop et al., 1984).

Currently, there is not authorized recommendation for the dose and withdrawal period of using antibiotics in the case of intravaginal sponges used to synchronize estrus. The objective of this study was to determine if 
ewe milk would show signs of residual antibiotics after treating ewes with intravaginal progestagen sponges impregnated with antibiotics by using 5 different methods of antimicrobial screening.

This experiment was approved by the Animal Ethics Committee of the University of Castilla-La Mancha and was carried out in November 2007 in the National Flock of the Manchego breed (Finca de La Nava, Valdepeñas, Spain). A total of 16 healthy lactating Manchego ewes (65 $\pm 3 \mathrm{~d}$ postpartum), all approximately equal in age $(2.22 \pm 0.04 \mathrm{yr})$, BW $(60.71 \pm 0.91 \mathrm{~kg})$, and daily milk yield $(1.59 \pm 0.10 \mathrm{~L} / \mathrm{d})$, were selected for this study. Ewes were housed and fed with the rest of the herd. None of them had a previous history of clinical mastitis, and all ewes showed SCC less than 90,000 cells $/ \mathrm{mL}$ before the start of the study. Ewes were machine-milked twice a day (at 0900 and $1800 \mathrm{~h}$ ). They received no drugs before commencement of the experiment, which took place in wk 4 of the milking period, after weaning lambs $(30 \pm 2 \mathrm{~d})$. Ewes were randomly divided into 3 groups. The antibiotic group consisted of ewes $(n=8)$ treated with an intravaginally inserted sponge impregnated with a low dose of synthetic progestagen $(20 \mathrm{mg}$ of fluorogestone acetate, Chrono-gest CR, Intervet, Salamanca, Spain). Before insertion, bags of 25 sponges were dusted according to the normal veterinary practices with an antibiotic powder preparation (Veterin-Micipen, Intervet, Salamanca, Spain) consisting of bencilpenicillin procaine $(1,000,000 \mathrm{IU})$ plus dihydrostreptomycin ( $1 \mathrm{~g})$. A second group of ewes $(n=4)$ was treated equally except the sponges were not dusted with antibiotic powder. And a third control group went without any treatment $(n=4)$. Immediately before animals were allotted, individual samples of milk were analyzed to assure antibiotic-free milk. The withdrawal period recommended by manufacturers for the antibiotic preparation used i.m. is $4 \mathrm{~d}$.

Following sponge insertion (at $1000 \mathrm{~h}$ ), each group of ewes was individually machine-milked twice a day (the first milking being at $1800 \mathrm{~h}$ on the first day). Additional milk samples were collected during every subsequent milking session (at 0900 and $1800 \mathrm{~h}$ ) until 9 samples were gathered from each sheep. After each sheep was milked, samples $(100 \mathrm{~mL} /$ ewe at every milking session) were gathered from the individual recorder jar and placed, without the application of any form of preservative, in disposable plastic containers and kept at $4^{\circ} \mathrm{C}$ until they were analyzed.

All milk samples were analyzed within $24 \mathrm{~h}$ of collection through 5 tests: 4 microbial growth inhibition assays done simultaneously, each containing Geobacillus stearothermophilus var. calidolactis and 1 proteinbased receptor assay (New SNAP Beta-lactams). In all 5 tests, milk from healthy animals that had not received feed or drug treatments and had been proved to be free of antimicrobials was used as the negative control. For the positive control, negative milk samples spiked with $10 \mu \mathrm{g} / \mathrm{kg}$ of benzyl penicillin G (Pen Na, Sigma, St. Louis, MO) were used. After adding 100 $\mu \mathrm{L}$ of milk samples into single wells of brilliant black reduction AiM inhibitor test (BRT; AIM-Analytik in Milch Produktions-und Vertriebs BmbH, Munich, Germany), CMT Copan test (CMT; Copan, Brescia, Italy), Delvotest MSC (DSM Food Specialties, Delft, the Netherlands), or Eclipse 100 test (Zeu-Inmunotec, 2003), plates were incubated in a water bath at $64 \pm$ $1^{\circ} \mathrm{C}$ for the time necessary for the negative control to turn yellow. Thus, it took $3 \mathrm{~h}$ (Molina et al., 2003b) for the BRT test, $3 \mathrm{~h}$ and $15 \mathrm{~min}$ for the CMT (Roca et al., 2007) and Delvotest tests (DSM, 2001), and $3 \mathrm{~h}$ before preincubation $1 \mathrm{~h}$ at room temperature for milk and antibiotic diffusion for Eclipse test (Roca et al., 2007). Visual evaluation was completed independently by 3 trained observers and thereby judged qualitatively as negative, doubtful, or positive (Berruga et al., 2003). As a result, visual interpretations with at least 2 coinciding readings were considered. The new SNAP BetaLactam (SNAP, IDEXX Laboratories Inc., Westbrook, $\mathrm{ME})$ is a specific test for the detection of B-lactams. Milk samples $(450 \pm 50 \mu \mathrm{L})$ were assayed according to the manufacturer's label instructions (IDEXX, 2007). Visual evaluation by comparison with the color table, supplied by the manufacturer, was performed independently by 3 trained individuals, just as the interpretation of microbial tests was done. Detection limits of each method for penicillin and streptomycin are shown in Table 1.

Data were organized using a logistic regression model (Agresti, 1990). The positive and doubtful results from the different evaluations were grouped as positive plus doubtful to assess these qualitative variables at $2 \mathrm{lev}$ els (negative and positive plus doubtful). To evaluate the influence of the milking session on the results of the 5 screening tests studied, a logistic regression procedure from Statgraphics Plus 5.1 (Manugistics Inc., Rockville, MD) was employed. Variables were analyzed using the following logistic model:

$$
L_{i j}=\operatorname{logit}\left[P_{i j}\right]=B_{0}+B_{1}[\mathrm{MO}]_{\mathrm{i}}+\varepsilon_{\mathrm{ij}},
$$

where $L_{i j}$ is the variable logit $\left\{\right.$ i.e., $\ln \left[P_{i j} /\left(1-P_{i j}\right)\right]$; $\left[P_{i j}\right]$ is the probability of positive plus doubtful response; [ 1 - $P_{i j}$ is the probability of negative response; $B_{0}$ is the intercept; $B_{1}$ is the estimated parameter for the model; $[\mathrm{MO}]_{i}$ is the effect of milking session $(1,2,3,4,5,6$, and 9); and $\varepsilon_{\mathrm{ij}}$ is the residual error. The concordance coefficient was applied as a rank correlation between the observed responses and predicted probabilities. 
Table 1. Detection limits ${ }^{1}(\mu \mathrm{g} / \mathrm{kg})$ of antibiotic tested by various methods in cows' or ewes' milk

\begin{tabular}{lccl}
\hline Assay & $\begin{array}{c}\text { Penicillin } \\
\text { (MRL } 2: 4 \mu \mathrm{g} / \mathrm{kg})\end{array}$ & $\begin{array}{c}\text { DH-streptomycin } \\
\text { (MRL: } 200 \mu \mathrm{g} / \mathrm{kg})\end{array}$ & Reference \\
\hline BRT $^{3}$ & $2^{1}$ & $6,000^{1}$ & $\begin{array}{l}\text { Molina et al. (2003b); } \\
\text { AiM (2006) }\end{array}$ \\
CMT Copan & 2 to 3 & 1,000 & Copan (2003) \\
Delvotest MCS & 2 & - & DSM (2001) \\
Eclipse 100 & $5^{1}$ & $10,100^{1}$ & Montero et al. (2005) \\
New SNAP & 2 to 3 & - & IDEXX (2007) \\
Beta-lactams & & - & \\
\hline
\end{tabular}

${ }^{1}$ Detection limits calculated in ewes' milk.

${ }^{2} \mathrm{MRL}=$ maximum residue limits are established by the European Union (EU regulation 2237/91).

${ }^{3} \mathrm{BRT}=$ brilliant black reduction AiM inhibitor test; CMT = CMT Copan test.

Milk from animals corresponding to the groups where antibiotics were not used did not show positive or doubtful responses in any of the 9 milkings from which samples were collected and analyzed (data not shown). However, at the first milking, after intravaginal sponge application, milk from several animals belonging to the antibiotic-treated group showed positive or doubtful responses for one or more tests (Figure 1). All tests detected that over half the animals eliminated antibiotic residues (positive or doubtful responses) as of the first milking session. Following the first milking, the BRT test detected some doubtful responses up to the fifth milking session, and the SNAP test detected 1 positive animal up to the third. The tests used in this experiment have a high level of sensitivity for the detection of penicillin residues, from 2 to $5 \mathrm{\mu g} / \mathrm{kg}$ (Table 1 ), but none of them are able to detect dihydrostreptomycin at the MRL level. Moreover, the SNAP test is a specific test for the detection of B-lactam antibiotic. Therefore, although it is possible that the dihydrostreptomycin could have remained and contaminated milk, it is more probable that penicillin was the antibiotic detected by the 5 tests. Screening tests unsuited for the detection of dihydrostreptomycin were chosen because, when the experiment took place, there were no available commercial screening tests able to detect this aminoglycoside at the MRL level. Most of the microbial screening tests are based on the inhibition of $G$. stearothermophilus var. calidolactis, a bacterium with a high sensitivity to B-lactams, but a poor capacity to detect dihydrostreptomycin (Molina et al., 2003b; Montero et al., 2005). Because penicillin is the only antibiotic potentially detectable by the tests used in this study, it is safe to assume that it was mainly their residues that were detected in the milk. However, the interaction of both antibiotics could have increased the probability of residue detection in the microbial tests.

The results of the logistic model used to estimate the results of the screening methods are summarized in Table 2, and showed that for all assay methods the effect of milking order was significant. According to these regression models, there is a high risk of milk contamination from the animals treated with sponges impregnated with antibiotics at levels detectable by commercial screening tests for at least 1 or 2 consecutive milkings.

According to Bishop et al. (1984), after the administration of antibiotics for vaginal infections, the passage of antibiotics from the vaginal membrane into blood and milk is possible. Several authors have found antibiotic residues in milk after the intrauterine administration (Miller and Bergt, 1974; Black et al., 1979; Bishop et

Table 2. Summary of the logistic regression model coefficients for antibiotic residue depletion in ewe milk after the insertion of intravaginal sponges (for estrus synchronization) impregnated with a powder preparation of antibiotics ${ }^{1}$

\begin{tabular}{lrrrc}
\hline Assay & \multicolumn{1}{c}{ B $^{2}$} & \multicolumn{1}{c}{$6_{1}$} & $\mathrm{C}$ & $P$-value \\
\hline BRT $^{3}$ & 0.0295 & -0.5118 & 17.37 & 0.0021 \\
CMT Copan $^{3}$ & 17.9903 & -17.9903 & 64.11 & 0.0000 \\
Delvotest MCS & 2.3247 & -2.7689 & 52.13 & 0.0000 \\
Eclipse 100 & 16.9933 & -17.5042 & 57.56 & 0.0002 \\
New SNAP Beta-lactams & 1.9527 & -1.6056 & 47.75 & 0.0000 \\
\hline
\end{tabular}

${ }^{1}$ Veterin Micipen (bencilpenicillin procaine 1,000,000 IU and DH-streptomycin $1 \mathrm{~g}$ ).

${ }^{2} B_{0}$ is the intercept; $B_{1}$ was used to estimate the frequency of "positive + doubtful/negative" cases; $C$ is the concordance coefficient.

${ }^{3} \mathrm{BRT}=$ brilliant black reduction AiM inhibitor test; $\mathrm{CMT}=\mathrm{CMT}$ Copan test. 


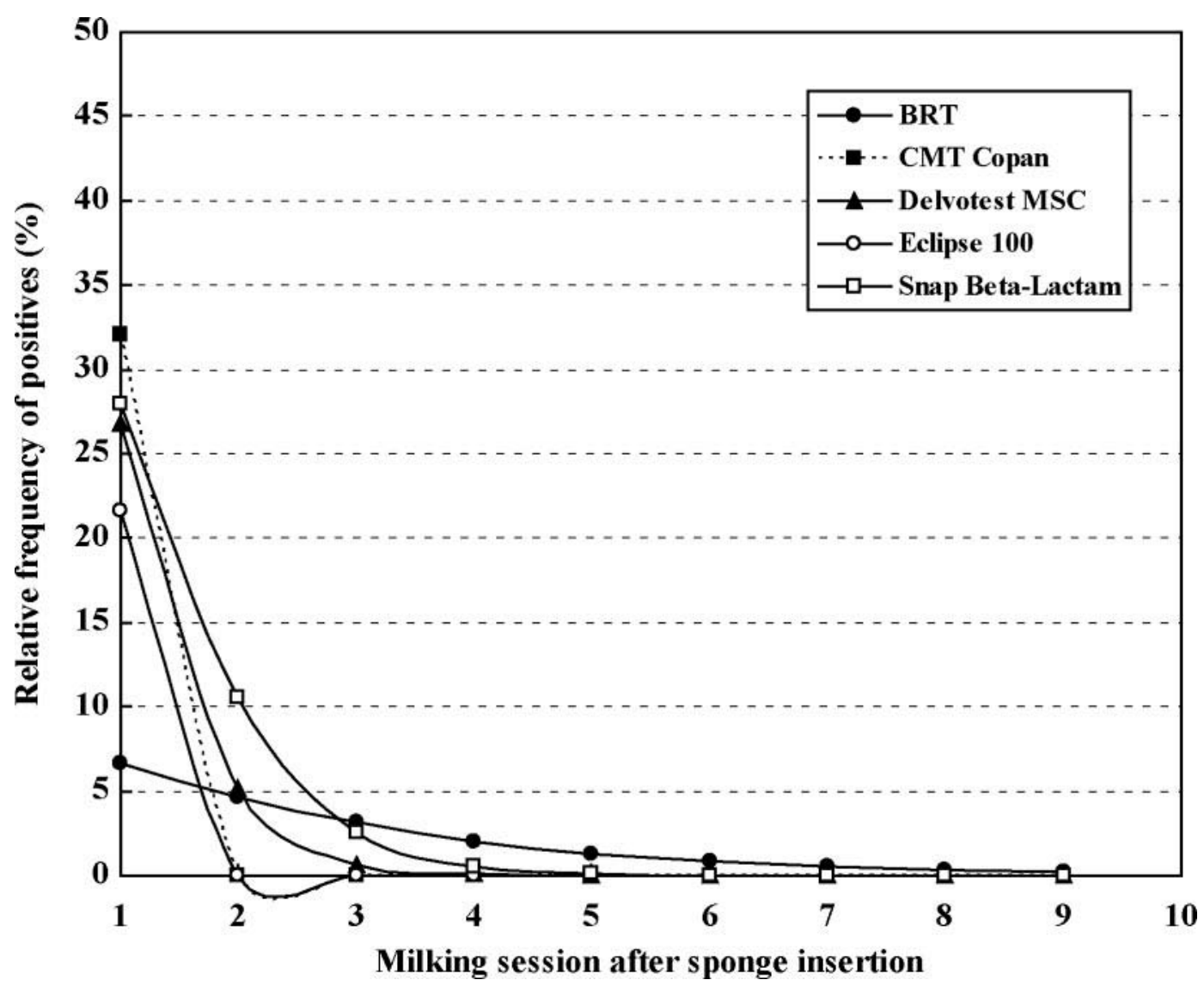

Figure 1. Relative frequency of positive plus doubtful cases in milk after the insertion of intravaginal sponges (for estrus synchronization) impregnated with a powder preparation of antibiotic using the Brilliant Black Reduction AiM inhibitor test (BRT, AIM-Analytik in Milch Produktions-und Vertriebs BmbH, Munich, Germany; •), CMT Copan (Copan, Brescia, Italy; a), Delvotest MSC (DSM Food, Delft, the Netherlands; $\mathbf{\Delta}$ ), Eclipse 100 (ZEU-Inmunotec, 2003; ○), and new SNAP Beta-Lactam (SNAP, IDEXX Laboratories Inc., Westbrook, ME; 口) tests.

al., 1984). In contrast, Henningson et al. (1963) did not observe antibiotic residues after the intravaginal administration of nitrofurazone or the intrauterine administration of penicillin plus dihydrostreptomycin at any time during the course of the treatments; however, this could be due to poorer test sensitivity levels used in their study.

The use of antibiotics applied with intravaginal sponges is a veterinary practice commonly used on sheep to prevent posterior vaginitis, but there are no specific protocols established by pharmaceutical laboratories. Pharmaceutical laboratories should be careful in recommending unofficial use of antibiotics because they might provoke misunderstandings as users may not be conscious of the proper usage of a drug with an established MRL. The extra-label use is regulated by the European Directive 2001/82/EC and indicates that when this additional application is used, the withdrawal period for milk should be no less than $7 \mathrm{~d}$. As several authors have mentioned (Kridli et al., 2006; Suárez et al., 2006), the use of antibiotics to prevent infections might be necessary; therefore, to forbid their use is not the solution. Rather, the establishment of correct application standards and withdrawal periods based on a specific study of their pharmacokinetics in milk is needed, to avoid long, unnecessary holding periods.

The main conclusion of this work was that a potential risk of finding antibiotic residues in milk exists as a consequence of the use of vaginitis-preventing antibiotics applied with intravaginal sponges for estrus synchronization in ewes, and therefore, guidelines for withdrawal periods following the use of antibiotics applied jointly in the sponges utilized for ewe synchronization should be established.

\section{ACKNOWLEDGMENTS}

The authors would like to thank the personnel from CERSYRA (JJCC Castilla-La Mancha, Spain) for their valuable help in the analyses, and A. Holdren (UCLM, 
Albacete, Spain) for his assistance with the preparation of this manuscript in English. Also, the authors are grateful to AIM-Analytik in Milch Produktionsund Vertriebs GmbH (München, Germany), Copan (Brescia, Italy), DSM Food Specialties (Delft, the Netherlands), Tecasa (Madrid, Spain), and ZEU-Inmunotec (Zaragoza, Spain) for their support.

\section{REFERENCES}

Agresti, A. 1990. Categorical Data Analysis. John Wiley \& Sons, New York, NY.

AiM. 2006. Detection sensitivities of AiM BRT Testsystems towards selected antiinfectives in cow milk, $\mu \mathrm{g} / \mathrm{kg}(\mathrm{ng} / \mathrm{mL} ; \mathrm{ppb})$. http:// www.aimbavaria.com/information/detection/index.htm Accessed Oct. 28, 2007.

Barillet, F., C. Marie, M. Jacquin, G. Lagriffoul, and J. M. Astruc. 2001. The French Lacaune dairy sheep breed: Use in France and abroad in the last 40 years. Livest. Prod. Sci. 71:17-29.

Berruga, M. I., M. Yamaki, R. L. Althaus, M. P. Molina, and A. Molina. 2003. Performances of antibiotic screening tests in determining the persistence of penicillin residues in ewe's milk. J. Food Prot. 66:2097-2102.

Bishop, J. R., A. B. Bodine, G. D. O'Dell, and J. J. Janzen. 1984 Retention data for antibiotics commonly used for bovine infections. J. Dairy Sci. 67:437-440.

Black, W. D., A. L. Mackay, P. A. Doig, and M. J. Claxton. 1979. A study of drug residues in milk following intrauterine infusion of antibacterial drugs in lactating cows. Can. Vet. J. 20:354-357.

Copan. 2003. CMT-Copan Milk Test for the detection of antibiotics and Sulphonamides in milk and milk products, Copan Italia s.p.a., Brescia, Italy. http://www.copanswabs.com/products/cmt/ Accessed Jan. 4, 2008.

DSM. 2001. Delvotest MCS official milk screening test in France. http://www.dsm.com/en_US/downloads/dfs/Delvotest_en.pdf Accessed Oct. 21, 2007.

European Medicines Evaluation Agency. 1999. Final Report: Antibiotic Resistance in the European Union associated with Therapeutic Use of Veterinary Medicines - Report and Qualitative Risk Assessment by the Committee for Veterinary Medicinal Products. EMEA/CVMP/342/99 Final Report. http://www.emea. europa.eu/pdfs/vet/regaffair/034299ENC.pdf. Accessed Jan. 10, 2002.

Henningson, W., V. Hurst, S. L. Moore, and J. W. Nelly. 1963. Effect of intrauterine infusion of penicillin-streptomycin and furacin and vaginal deposition of chemical residue levels in milk. J. Dairy Sci. 46:195-196.

IDEXX. 2007. New SNAP Beta-Lactam Test Kit (penicillin G, amoxicillin, ampicillin, ceftiofur and cephapirin) validated for raw, commingled cow milk. http://www.idexx.com/dairy/snap/ newsnapinstructions.pdf Accessed Oct. 21, 2007.

Kridli, R. T., M. Q. Hussein, H. A. Mundi, and J. M. Al-Khazaleh. 2006. Reproductive performance of hormonally-treated anestrous Awassi ewes. Anim. Reprod. 3:347-352.

Miller, G. E., and G. P. Bergt. 1974. Oxytetracycline in bovina plasma, milk, and urine after intrauterine administration. J. Dairy Sci. 59:315-317.

Mitchell, J. M., M. W. Griffiths, S. A. McEwen, W. B. McNab, and A. J. Yee. 1998. Antimicrobial drug residues in milk and meat: Causes, concerns, prevalence, regulations, tests, and test performance. J. Food Prot. 61:742-756.

Molina, A., M. P. Molina, R. L. Althaus, and L. Gallego. 2003a. Residue persistence in sheep milk following antibiotic therapy. Vet. J. 165:84-89.

Molina, M. P., R. L. Althaus, A. Molina, A. Torres, and N. Fernández. 2003b. Antimicrobial agent detection in ewe milk by microbial inhibitor test (Brilliant Black Reduction Test- BRT). Int. Dairy J. $13: 821-826$

Montero, A., R. L. Althaus, A. Molina, I. Berruga, and M. P. Molina. 2005. Detection of antimicrobial agents by a specific microbiological method (Eclipse 100ov) for ewe milk. Small Rumin. Res. 57:229-237.

Mourot, D., and S. Loussouarn. 1981. Sensibilité des ferments lactiques aux antibiotiques utilisés en médicine vétérinarie. Rev. Med. Vet. 157:175-177.

Roca, M., M. I. Berruga, A. Molina, R. L. Althaus, and M. P. Molina. 2007. Influencia de factores metodológicos sobre los métodos microbiologicos de detección de inhibidores en leche de oveja Pages 89-92 in Proc. XXXII Jornadas Científicas y XI Jornadas Internacionales de la Sociedad Española de Ovinotecnia y Caprinotecnia. S.E.O.C., Mallorca, Spain.

Suárez, G., P. Zunino, H. Carol, and R. Ungerfeld. 2006. Changes in the aerobic vaginal bacterial mucous load and assessment of the susceptibility to antibiotics after treatment with intravaginal sponges in anestrous ewes. Small Rumin. Res. 63:39-43.

Ugarte, E., M. Serrano, L. F. De la Fuente, M. D. Pérez-Guzmán, L. Alfonso, and J. P. Gutierrez. 2002. Situación actual de los programas de mejora genética en ovino de leche. ITEA 98A:102117.

Zeu-Inmunotec. 2003. Eclipse 100: Test para la detección de inhibidores en leche. Technical Report, Version 3. Ed. ZEU. Inmunotec, S.L., Zaragoza, Spain. 